\title{
Overview on Biosensors for Detection of Organophosphate Pesticides
}

\author{
Jitendra Kumar ${ }^{1,2}$ and Jose Savio Melo ${ }^{1,2 *}$ \\ ${ }^{1}$ Nuclear Agriculture and Biotechnology Division, Bhabha Atomic Research Centre, Trombay, Mumbai,, India \\ ${ }^{2}$ Homi Bhabha National Institute, Anushakti Nagar, Mumbai, India
}

Submission: Feb 06, 2017; Published: June 16, 2017

*Corresponding author: Jose Savio Melo, Homi Bhabha National Institute, Anushakti Nagar Mumbai-400 094, India, Fax: +9122 25505151; Email: jsmelo@barc.govin

\begin{abstract}
In agriculture pesticides play an important role to control the pests. The use of organophosphate pesticides has caused serious problems to environment, human health and ecosystem. Thus, monitoring of these pesticides is extremely important. Researchers have been trying to develop biosensors for easy, online and prompt monitoring of organophosphate pesticides. This review is an overview on the biosensors developed for the detection of organophosphate pesticides. It briefly summarizes what has been covered in the previously published reviews as well as highlights the recent developments in the detection of organophosphate pesticides biosensors.
\end{abstract}

\section{Introduction}

Pesticides (herbicides, fungicides or insecticides) play an important role in agriculture to control the pests and increase the productivity to meet the demand of foods by a remarkably growing population. Pesticides application thus became one of the important inputs for the high production of corn and wheat in USA and UK, respectively. It also increased the crop production in China and India [1-4]. Although extensive use of pesticides improved in securing enough crop production worldwide however; these pesticides are equally toxic or harmful to nontarget organisms like mammals, birds etc and thus their presence in excess can cause serious health and environmental problems. Pesticides have thus become environmental pollutants as they are often found in soil, water, atmosphere and agricultural products, in harmful levels, posing an environmental threat. Its residual presence in agricultural products and foods can also exhibit acute or chronic toxicity on human health. Even at low levels, it can cause adverse effects on humans, plants, animals and ecosystems. Thus, monitoring of these pesticide and its residues become extremely important to ensure that agricultural products have permitted levels of pesticides [5-6].

Majority of pesticides belong to four classes, namely organochlorines, organophosphates, carbamates and pyrethroids. Organophosphates pesticides are a class of insecticides, of which many are highly toxic [7]. Until the 21st century, they were among the most widely used insecticides which included parathion, malathion, methyl parathion, chlorpyrifos, diazinon, dichlorvos, dimethoate, monocrotophos and profenofos. Organophosphate pesticides cause toxicity by inhibiting acetylcholinesterase enzyme [8]. It acts as a poison to insects and other animals, such as birds, amphibians and mammals, primarily by phosphorylating the acetylcholinesterase enzyme (AChE) present at nerve endings. This leads to the loss of available AChE and because of the excess acetylcholine (ACh, the impulse-transmitting substance), the effected organ becomes over stimulated. The enzyme is critical to control the transmission of nerve impulse from nerve fibers to the smooth and skeletal muscle cells, secretary cells and autonomic ganglia, and within the central nervous system (CNS). Once the enzyme reaches a critical level due to inactivation by phosphorylation, symptoms and signs of cholinergic poisoning get manifested [9].

Because of the extensive amount of organophosphate pesticides being used commonly and it's adverse effect on health and environment, it has become very important to develop a sensitive, specific, accurate and online method of pesticide detection. Environmental Protection Agency (EPA) has fixed the levels for pesticides detection, which is a challenge for researchers worldwide [10-11]. Coupled to selective detectors many traditional analytical chromatographic and spectrometric methods have been exploited for pesticide analysis due to their sensitivity, accuracy and reliability, but they require not only 
expensive equipments but also highly-trained technicians. Also these traditional techniques are time-consuming and laborious because it requires pre sample preparation before analysis. Over a course of time, researchers have put efforts to develop promising alternatives for the detection of pesticides which can be used for easy, online and prompt detection with comparable accuracy and sensitivity. Also approach is such that the sample preparation can be avoided and minimized. A biosensor is a analytical device that integrates an immobilized biological element (e.g. enzyme, DNA probe, antibody) that recognizes the analyte (e.g. enzyme substrate, complementary DNA, antigen) with a transducer (Electrochemical, optical etc.) and the signal generated due to interaction between analyte and biological element is proportional to the concentration of analyte [12-13].

This review has two sections, in the first, we briefly summarize the aspects covered in the previously published reviews on biosensor for organophosphates pesticides and in second section we highlight the recent developments in biosensors for detection of organophosphate pesticides.

\section{Summary of the earlier published reviews}

In this section we briefly summarize the aspects covered in the previously published reviews on biosensor for organophosphates pesticides in chronological order for the past 20 years (1996 to 2016). Skladal (1996), reviewed the studies on cholinesterase based biosensors for analysis of organophosphate and carbamate pesticides. In this review, previously published 112 papers were discussed with respect to bioanalytical application of acetylcholinesterase and butyrylcholiesterase enzymes. Several methods for measurement of enzyme activity were introduced together with suitable transducers like potentiometric, amperometric, spectrophotometric and fluorimetric. The detection limits for paraoxon as the reference pesticide was compared with various techniques and the application of biosensors using real samples were summarized [14]. Rekha et al. [15] reviewed on biosensors for detection of organophosphate pesticides wherein they covered the aspects on biological receptors (enzyme, immune, receptor, cells and tissues) based biosensors and also discussed the desirable characteristic of biosensor as well as parameters affecting the performance of biosensors.

Mulchandani et al. [16] reported about the development, characterization and applications of organophosphorus hydrolase-based potentiometric, amperometric and optical biosensors. Besides they also explained their own finding of direct, selective, rapid and simple determination of organophosphate pesticides, which was achieved by integrating organophosphorus hydrolase with electrochemical and optical transducers. Organophosphorus hydrolase catalyzes the hydrolysis of a wide range of organophosphate compounds, releasing an acid and an alcohol that can be detected directly. Suri et al. [17] explained about immunosensors for pesticide analysis. This review article reported the status of immunosensors, highlighting their potential benefits and limitations for pesticide analysis. The basic criteria for generating specific antibodies against lowmolecular-mass pesticides, which are usually nonimmunogenic in nature were briefly discussed. The article also described the fundamentals of important transducer technologies and their use in immunosensor development. Trojanowicz [18] reviewed the numerous biosensing methods for detection of pesticides using integrated enzymatic biosensors and immunosensors. He explained that enzymatic determination of pesticides is most often based on inhibition of the activity of selected enzymes such as cholinesterases (ChE), organophosphorus hydrolase $(\mathrm{OPH})$, alkaline and acid phosphatase, ascorbate oxidase, acetolactate synthase and aldehyde dehydrogenase. Enzymatic biosensors developed using various electrochemical signal transducers, different methods of enzyme immobilization and various measuring methodologies were discussed. In this review he explained how detection levels can be improved by the use of recombinant mutants for enzyme. Also another area dealt with the design of microbial and photosystem-based biosensors with electrochemical transducer [18].

Amine et al. [19] dealt with the aspects on enzyme inhibitionbased biosensors for determination of pollutants and toxic compounds in a wide range of samples related to food safety and environmental monitoring. They explained the different enzymes implicated in the inhibition, different transducers forming the sensing devices and the different contaminants analyzed. Besides different applications, approaches for enzyme immobilization and inhibition mechanism were discussed. Zhang \& Yang [20] reviewed about biosensors associated with ChE for detection of pesticide residues and highlighted how to overcome the problems inherent to $\mathrm{ChE}$ inhibition analysis, namely selectivity, accuracy, irreversible inhibition and matrix effect. More sensitive genetically engineered $\mathrm{ChE}$ variants and sophisticated parallel detection systems were also envisaged in the review. Dzyadevych et al. [21] focused on enzyme biosensors based on ion-selective field-effect transistors in their review article. The key theoretical principles of ion-selective field-effect transistor coupled with their application in bioanalytical practice, some specifics of modern microtechnologies for their creation and measurement schemes with set-ups were discussed in the review. The achievements in the creation of enzyme biosensors based on ion- selective field-effect transistors and prospects for their application were also described in detail. Anzai [22] reviewed about electrochemical biosensors for detecting organophosphorus pesticides and nerve agents. The sensors used AChE and choline oxidase (ChOx) for converting the AChEgenerated choline into betaine and hydrogen peroxide (H2O2), which is electrochemically oxidized at the electrode surface to produce the output signal of the sensor. When AChE inhibitors are present, the output signal of the sensor is suppressed. However If acetylthiocholine is used as a substrate for AChE, one can eliminate $\mathrm{ChOx}$ because enzymatically generated thiocholine is electrochemically active and thus directly oxidized at the electrode. One of the drawbacks of the AChE-based biosensors arises from the fact that the sensors indirectly detect the signal 
based on the inhibition of the AChE-catalyzed reaction. On the other hand OPH based amperometric sensors can be used for directly obtaining the output signal. OPH catalyzes the hydrolysis of organophosphorus compounds like parathion and VX to produce electrochemically active compounds such as p-nitrophenol and thiols respectively. Thus OPH-based sensors can be used for detecting these compounds directly. Since these biosensors could be easily fabricated at relatively low cost and made portable they can be useful for on-site measurements of organophosphorus pesticides and nerve agents [22].

Pohanka et al. [23] reviewed on ChE based biosensor construction. In this review, some strategies convenient for biosensor construction were presented. Solutions for cholinesterase immobilization and output signal monitoring were presented as the basic presumptions for successful biosensor construction. Pohanka et al. [24] again reviewed the progress of biosensors based on AChE or butyrylcholinesterase (BChE). Here inhibition of selected enzymes by various compounds, such as organophosphorus and carbamate pesticides, nerve agents (e.g. sarin or VX), and other natural toxins (e.g. aflatoxins) were discussed. Also this review focused on novel trends within such biosensors using recombinant proteins, microelectrodes and immobilization protocols related to nanotechnologies.

Van Dyk \& Pletschke [25] reviewed about the detection of organochlorine, organophosphate and carbamate pesticides in the environment. They focused on enzymatic methods as an alternative method for detection of these pesticides. The main enzymes that have been utilized in this regard are AChE, $\mathrm{BChE}$, alkaline phosphatase, $\mathrm{OPH}$ and tyrosinase. The enzymatic methods were based on the activation or inhibition of the enzyme by the pesticide and are proportional to the concentration of the pesticide. Research on enzymatic methods of detection, as well as some of the problems and challenges associated with these methods, was extensively discussed in this review. It was explained that these methods can serve as a tool for screening large samples which can be followed up with the more traditional chromatographic methods of analysis [10]. Liang \& Hay [25] reported on literature published in 2010 about analytical methods for pesticides and herbicides including extraction methods, chromatographic or mass spectrometric techniques, electrochemical techniques, spectrophotometric techniques, chemiluminescence and fluorescence methods, sensors, biochemical assays and immunoassays, and miscellaneous techniques [25]. Rassaei et al. [26] reviewed the state-of-the-art application of nanoparticles (NPs) in electrochemical analysis of environmental pollutants. Various methods for preparing NPs and modifying electrode surfaces with NPs were summarized. Further they described how metal and metal-oxide NPs can affect the performance in terms of sensitivity and selectivity. The beneficial use of NPs in constructing electrochemical sensors for environmental monitoring and the future challenges were discussed.

Marrazza [27] reviewed about piezoelectric biosensors for organophosphate and carbamate pesticides. Among all the physical transducers, piezoelectric systems have gained attraction due to their simplicity, low instrumentation costs, possibility for real-time and label-free detection and generally high sensitivity. Zhang et al. [28] reviewed the nanomaterialbased electrochemical and immunoassay biosensors for environmental and biological monitoring of organophosphorus pesticides and nerve agents. Nanomaterials function as signal transducers to mediate current flow or as recognition agents. It presented electroactive tags to indicate the detection of analyte. Kumar et al. [1] reviewed the recent advancements in sensing techniques for organophosphate pesticides using functional materials like fluorescent nanomaterials and molecular imprints and further discussed about their performance, challenges and opportunities.

Recently in a book chapter we have reviewed the status of research in the field of microbial based biosensors for the detection of methyl parathion pesticides [29]. In this chapter, we have explained how microbial biosensors are a good alternative to enzyme biosensors because they provide the benefits of low cost and improved stability to the enzymes. Also we summarized the trend of our own research on microbial biosensors from single to multiple samples analysis. The first biosensor was an optical microbial biosensor based on immobilization of whole cells of Flavobacterium sp. containing OPH on glass fibre filters by adsorption method and was used as a disposable biocomponent in association with optical fibre transducer for detection of methyl parathion pesticide. The biosensor biocomponent was disposable in nature [30]. Multiple sample analysis using developed reusable biocomponents have been developed as second and third biosensor [31-33]. Details of the recent works published after 2010 are included in later section.

\section{Recent developments in biosensors for detection of organophosphate pesticides}

Table 1: Recent developments of biosensors for detection of organophosphate pesticides.

1a: During period 2010 to 2013

\begin{tabular}{|c|c|c|c|}
\hline $\begin{array}{c}\text { Organophosphate } \\
\text { pesticides }\end{array}$ & $\begin{array}{c}\text { Biological components integrated with functional } \\
\text { materials and support }\end{array}$ & $\begin{array}{c}\text { Transducers } \\
\text { Detection Limit/ } \\
\text { Detection ranges }\end{array}$ & Amperometric \\
\hline Dimethoate & $\begin{array}{c}\text { AChE-MWCNTs- } \beta \text {-cyclodextrin }(\beta-\mathrm{CD}) \text { composite modified } \\
\text { glassy carbon electrode }\end{array}$ & $\begin{array}{c}0.01-2.44 \mu \mathrm{M} \\
2.44-10.00 \mu \mathrm{M}\end{array}$ \\
\hline
\end{tabular}




\section{Current Trends in Biomedical Engineering \& Biosciences}

\begin{tabular}{|c|c|c|c|c|}
\hline Malathion & $\begin{array}{l}\text { AChE on polypyrrole (PPy) and polyaniline (PANI) } \\
\text { copolymer doped with MWCNTs }\end{array}$ & Amperometric & $\begin{array}{l}0.01-0.5 \mu \mathrm{g} / \mathrm{mL} \\
1-25 \mu \mathrm{g} / \mathrm{mL} \\
1.0 \mathrm{ng} / \mathrm{mL}\end{array}$ & 35 \\
\hline Chloropyrifos & $\begin{array}{l}\text { AChE- covalent bonding to an } \\
\text { oxidized exfoliated graphite nanoplatelet (xGnPs)-chitosan } \\
\text { cross-linked composite }\end{array}$ & Electrochemical & $\begin{array}{l}0.005-0.039 \mathrm{mM} 0.064- \\
0.258 \mathrm{mM}\end{array}$ & 36 \\
\hline Chloropyrifos & $\begin{array}{l}\text { AChE- covalent bonding to an } \\
\text { oxidized exfoliated graphite nanoplatelet (xGnPs)-chitosan } \\
\text { cross-linked composite }\end{array}$ & Electrochemical & $\begin{array}{l}0.005-0.039 \mathrm{mM} 0.064- \\
0.258 \mathrm{mM}\end{array}$ & 36 \\
\hline Methyl parathion & $\begin{array}{l}\text { Recombinant E. coli having high periplasmic expression of } \\
\text { OPH }\end{array}$ & $\begin{array}{l}\text { Cyclic voltammetry } \\
\text { (CV) }\end{array}$ & $2-80 \mu \mathrm{M}$ & 31 \\
\hline Methyl parathion & Sphingomonas sp. with OPH immobilized on microplate & $\begin{array}{l}\text { Microplate based } \\
\text { Optical }\end{array}$ & $4-80 \mu \mathrm{M}$ & 32 \\
\hline Methyl parathion & 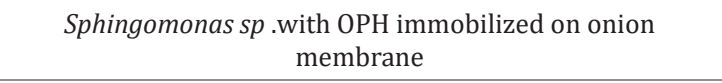 & $\begin{array}{l}\text { Microplate based } \\
\text { Optical }\end{array}$ & $4-80 \mu \mathrm{M}$ & 33 \\
\hline $\begin{array}{l}\text { Six organophosphate } \\
\text { pesticides }\end{array}$ & $\begin{array}{l}\text { AChE on Screen-printed in a novel automated instrument } \\
\text { incorporating a neural network program }\end{array}$ & Amperometric & $10^{-5}-10^{-9} \mathrm{M}$ & 37 \\
\hline Paraxon & $\begin{array}{c}\text { Esterase } 2 \text { from Alicyclobacillus } \\
\text { acidocaldarius immobilization on a nitrocellulose } \\
\text { membrane }\end{array}$ & Electrochemical & $2.75 \times 10^{-3} \mathrm{ppm}$ & 38 \\
\hline Chlorpyriphos-oxon & $\begin{array}{l}\text { poly(3,4- ethylenedioxythiophene) (PEDOT) conducting } \\
\text { ink to be incorporated in AChE- based screen printed }\end{array}$ & Electrochemical & $1 \cdot 10^{-10} \mathrm{M}$ & 40 \\
\hline $\begin{array}{l}\text { Chlorpyriphos-oxon, } \\
\text { Ethyl paraoxon } \\
\text { Malaoxon }\end{array}$ & -------------- & $\begin{array}{l}\text { Automated flow-based } \\
\text { biosensor }\end{array}$ & $5 \times 10^{-6}-5 \times 10^{-12} \mathrm{M}$ & 41 \\
\hline Malathion & $\begin{array}{c}\text { AChE covalent bonding to 1-butyl- 3-methylimidazolium } \\
\text { hexafluorophosphate (BMIMPF 6-graphene- chitosan } \\
\text { composite }\end{array}$ & Amperometric & $\begin{array}{l}0.1-1.0 \mathrm{nM} \\
1.0-10 \mathrm{nM}\end{array}$ & 43 \\
\hline $\begin{array}{l}\text { Ethyl paraoxon, } \\
\text { Monocroptophos, } \\
\text { Dichlorvos }\end{array}$ & 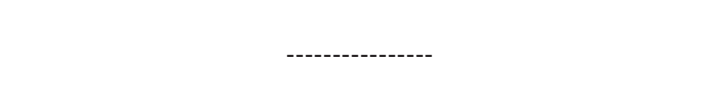 & $\begin{array}{l}\text { Amperometric flow- } \\
\text { injection system }\end{array}$ & $\begin{array}{l}\left(0.9 \times 10^{-12} \mathrm{M}\right) \\
(1.8 \times 10-12 \mathrm{M})\end{array}$ & 44 \\
\hline $\begin{array}{l}3 \text { OPs } \\
\text { Ethyl paraoxon, } \\
\text { Malaoxon, and } \\
\text { Chlorpyriphos-oxon }\end{array}$ & $\begin{array}{l}\text { Phosphotriesterase (PTE) was immobilized on an activated } \\
\text { Sepharose 4B via covalent coupling using an Omnifit glass } \\
\text { column }\end{array}$ & $\begin{array}{c}\text { Flow based AChE B394 } \\
\text { biosensor }\end{array}$ & ---------- & 42 \\
\hline Methyl parathion & $\begin{array}{c}\text { Layered double hydroxides (LDHs) as the immobilization } \\
\text { matrix of AChE }\end{array}$ & $\begin{array}{c}\text { Amperometric flow } \\
\text { injection analysis (FIA) }\end{array}$ & $0.005-0.3 \mu \mathrm{g} / \mathrm{mL}$ & 45 \\
\hline Paraxon & $\begin{array}{l}\text { PON1immobilized on a copper grid which also hosts } \mathrm{pH}- \\
\text { sensitive LC, 4-cyano-4'-pentylbiphenyl (5CB) doped with } \\
0.3 \% \text { of 4'-pentyl- biphenyl-4-carboxylic acid (PBA) }\end{array}$ & pH-sensitive & $1 \mu \mathrm{M}$ & 46 \\
\hline $\begin{array}{l}\text { Mixture of six } \\
\text { organophosphate } \\
\text { pesticides }\end{array}$ & $\begin{array}{l}\mathrm{OPH} \text { and MPH-GFP fusion on the cell surface of Escherichia } \\
\text { coli using the truncated ice nucleation protein (INPNC) and } \\
\text { Lpp-OmpA }\end{array}$ & Fluorescence & $0.2 \mathrm{mM}$ each & 47 \\
\hline
\end{tabular}

1b: 2014 to present.

\begin{tabular}{|c|c|c|c|c|}
\hline $\begin{array}{l}\text { Organophosphate } \\
\text { pesticides }\end{array}$ & $\begin{array}{l}\text { Biological components integrated with } \\
\text { functional materials and support }\end{array}$ & Transducers & $\begin{array}{l}\text { Detection Limit/ } \\
\text { Detection ranges }\end{array}$ & Ref. \\
\hline ethyl parathion & $\begin{array}{l}\text { AChE-QDs-GNs modified glassy carbon electrode } \\
\text { (GCE) }\end{array}$ & Electrochemiluminescence & $0.06 \mathrm{ng} / \mathrm{mL}$ & 48 \\
\hline Dichlorvos & $\begin{array}{l}\mathrm{AChE} /[\mathrm{BSmim}] \mathrm{HSO} \text { 4-AuNPs-porous carbon/BDD } \\
\text { electrode }\end{array}$ & $\begin{array}{c}\mathrm{CV} \\
\text { and EIS }\end{array}$ & $\begin{array}{c}4.5 \times 10^{-1} \\
3-4.5 \times 10^{-9} \mathrm{M}\end{array}$ & 49 \\
\hline $\begin{array}{l}\text { Diazinon Malathion } \\
\text { Chlorpyrifos } \\
\text { Profenofos }\end{array}$ & $\begin{array}{l}\text { OPH on a chitosan membrane by crosslinking it } \\
\text { with glutaraldehyde on screen printed electrode } \\
\text { printed electrode }\end{array}$ & Electrochemical & $0-100 \mathrm{ppb}$ & 50 \\
\hline $\begin{array}{l}\text { Chlorpyriphos-oxon } \\
\text { and Malaoxon }\end{array}$ & Genetically modified AChE coupled on SPEs & Potentiostat flow cell & $\begin{array}{l}5 \times 10^{-10}-5 \times 10^{-12} \mathrm{M} \\
1 \times 10^{-10}-9 \times 10^{-11} \mathrm{M}\end{array}$ & 51 \\
\hline
\end{tabular}


Current Trends in Biomedical Engineering \& Biosciences

\begin{tabular}{|c|c|c|c|c|}
\hline Paraxon & $\begin{array}{l}\text { Escherichia coli expressing OPH in the periplasmic } \\
\text { space and SWCNTs }\end{array}$ & Spectrophotometry (optical) & ------ & 53 \\
\hline $\begin{array}{l}\text { Parathion-methyl, } \\
\text { Monocrotophos and } \\
\text { Dimethoate }\end{array}$ & AchE with gold nanoparticles (AuNPs) & $\begin{array}{l}\text { Fluorescence resonance energy } \\
\text { transfer (FRET) }\end{array}$ & $\begin{array}{l}0.67 \mathrm{ng} / \mathrm{L} \\
23 \mathrm{ng} / \mathrm{L} \\
67 \mathrm{ng} / \mathrm{L}\end{array}$ & 54 \\
\hline Organophosphate & $\begin{array}{c}\text { polyanilinenanocrystalline } \\
\text { zeolite based acetylcholinesterase }\end{array}$ & & & 55 \\
\hline $\begin{array}{l}\text { Methyl parathion } \\
\text { Malathion }\end{array}$ & $\begin{array}{c}\text { Plant esterase-chitosan/gold } \\
\text { nanoparticles-graphene nanosheet (PLaE-CS/ } \\
\text { AuNPs-GNs) }\end{array}$ & Electrochemical & $\begin{array}{c}50 \mathrm{ppt}-200 \mathrm{ppb} \\
0.5-500 \mathrm{ppb}\end{array}$ & 56 \\
\hline Methyl parathion & AChE immobilized gold nanoshpere & Electrochemical & & 57 \\
\hline Organophosphate & $\begin{array}{c}\text { AchE on graphene/polyaniline (G/PANI) composite } \\
\text { film }\end{array}$ & Electrochemical & $38-194 \mathrm{ng} / \mathrm{mL}$ & 58 \\
\hline $\begin{array}{l}\text { Paraoxon and } \\
\text { Dimethoate }\end{array}$ & AChE/AuNRs/GCE & Electrochemical & $\begin{array}{l}1 \mathrm{nM}-5 \mu \mathrm{M} \\
5 \mathrm{nM}-1 \mu \mathrm{M}\end{array}$ & 59 \\
\hline Organophosphates & $\begin{array}{l}\text { Pd wormlike nanochains/graphitic carbon } \\
\text { nitride (Pd WLNCs/g-C3N4) nanocomposites and } \\
\text { acetylcholinesterase (AChE). }\end{array}$ & Electrochemical & $1.00 \mathrm{nM}-14.96 \mu \mathrm{M}$ & 60 \\
\hline Parathion Paraoxon & $\begin{array}{l}\text { Layer-by-layer (LbL) microarrays of QDs/AChE } \\
\text { microscopic dot arrays }\end{array}$ & Fluorescence intensity & $10 \mu \mathrm{g} / \mathrm{L}$ & 61 \\
\hline $\begin{array}{l}\text { Monocrotophos } \\
\text { Dichlorvos }\end{array}$ & $\begin{array}{l}\text { Acetylcholinesterase-zinc oxide modified platinum } \\
\text { electrode }\end{array}$ & Electrochemical & $\begin{array}{l}0.036 \text { and } 0.012 \mathrm{nM} \\
\text { respectively }\end{array}$ & 62 \\
\hline Dimethoate & AChE/ILGR/ Co304/CHI/GCE electrode & CV and EIS & $\begin{array}{l}5.0 \times 10^{-12} \text { to } \\
1.0 \times 10^{-7} \mathrm{M}\end{array}$ & 63 \\
\hline Malathion & AChE/PEDOT-MWCNTs/FTO & Electrochemical & $1 \mathrm{fM}-1 \mathrm{uM}$ & 64 \\
\hline $\begin{array}{l}\text { Methyl parathion } \\
\text { Parathion }\end{array}$ & ELP-OPH/BSA/TiO2NFs/c-MWCNTs & Amperometric & $10 \mathrm{nM} / 12 \mathrm{nM}$ & 65 \\
\hline Methyl parathion & $\begin{array}{l}\text { Sphingomonas sp.-fSi NP immobilized on the wells } \\
\text { of microplate }\end{array}$ & Optical transducer & $0.1-1 \mathrm{ppm}$ & 66 \\
\hline
\end{tabular}

In this section, we will discuss about the suitable biological components integrated with the different types of suitable supports including nano-materials, transducers used and detection limit/detection range of the pesticide biosensors developed in the last six years (from 2010 onwards) in a chronological order. The same has also been summarized in Table 1a \& 1b.

\section{During the period 2010 to 2013}

In 2010, Du et al., reported a highly sensitive amperometric biosensor for organophosphate pesticides using modified glassy carbon electrode with AChE immobilized on composite of multiwall carbon nanotubes (MWCNTs)- $\beta$-cyclodextrin ( $\beta$ CD). The good dispersibility and porous structures of MWCNTs$\beta$-CD composite provided a favorable microenvironment for AChE and maintained the bioactivity of AChE. It operated in the concentration range from 0.01 to 2.44 and 2.44 to $10.00 \mu \mathrm{M}$ of dimethoate, with a detection limit of $2 \mathrm{nM}$, based on the inhibition of dimethoate on AChE [34]. In another study Du et al. [35] immobilized AChE on polypyrrole (PPy) and polyaniline (PANI) copolymer doped with MWCNTs. The synthesized PAnPPy-MWCNTs copolymer exhibited a porous and homogeneous morphology which was ideal for entrapping the enzyme molecules. Also MWCNTs helped to promote the electrontransfer at a lower potential. catalyze the electro-oxidation of thiocholine, thus increasing its sensitivity. The sensor operated in the concentration range from 0.01 to $0.5 \mu \mathrm{g} / \mathrm{mL}$ and from 1 to $25 . \mu \mathrm{g} / \mathrm{mL}$, with a detection limit of $1.0 \mathrm{ng} / \mathrm{mL}$ of malathion, based on the inhibition principle with malathion. Ion et al. [36] reported a sensitive biosensor for chloropyrifos (CPF), developed by immobilizing AChE through covalent bonding to an oxidized exfoliated graphite nanoplatelet (xGnPs)-chitosan cross-linked composite. Because of the increased surface area and the conductive properties of the nano-material, the response of the sensor was a linear function of acetylthiocholine chloride (ATCl) concentration in two segments, one from 0.005 to $0.039 \mathrm{mM}$ and the second from $0.064 \mathrm{mM}$ to $0.258 \mathrm{mM}$. They reported that fabrication of the biosensor was simple, response was fast and the stability was acceptable. Kumar \& D'Souza [31] reported a microplate based biosensor in which biocomponent consisting of whole cells of Sphingomonas sp. JK bacteria were directly immobilized through cross-linking on the surface of the wells of polystyrene microplates (96 wells) using glutaraldehyde. The microplate based biosensor has advantage as it provided a convenient system for detecting multiple samples (96 reaction) in a single platform. Detection range of the 
biosensor was determined to be $4-80 \mu \mathrm{M}$ of methyl parathion. Also the microplate with the cells immobilized could be reused for 75 reactions [32]. Microplate technique provides a simpler alternative for the typical two-dimensional micropositioning, enabling to acquire the whole array simultaneously and making the measurement time independent of the number of wells in the plate.

In 2011, Kumar \& D'Souza [31] reported a modification wherein cells of Sphingomonas sp. were immobilized on inner epidermis of onion bulb scale by adsorption followed by cross-linking and then placed in the wells of microplate and associated with the optical transducer. The applicability of the cells immobilized onion membrane was also demonstrated with spiked samples [33]. It was concluded that the microplatebased biosensor provides an innovative concept where multiple samples of MP could be detected in very short period of time as well as biocomponent are reusable for analysis of more than one samples. Kumar and D'Souza [31] also reported an amperometric biosensors based on whole cells of recombinant Escherichia coli immobilized on the SPCE. The recombinant E. coli cells expressed high organophosphorus hydrolase activity. This enzyme hydrolyzes methyl parathion into p-nitrophenol and dimethyl thiophosphoric acid. Cyclic voltammograms were recorded before and after hydrolysis of methyl parathion and the changes in the current observed at $+0.1 \mathrm{~V}$ potential, because of redox behavior of the hydrolyzed product p-nitrophenol helped to quantify the analyte. Detection range of biosensor was between $2-80 \mu \mathrm{M}$ of methyl parathion. A single immobilized SPCE could be reused for 32 reactions and required only $20 \mu \mathrm{L}$ volume of the sample for analysis [31]. Crew et al. [37] reported a biosensor array based on six acetylcholinesterase enzymes for use in a novel automated instrument incorporating a neural network program. Electrochemical analysis was carried out using chronoamperometry. The array was calibrated with six organophosphate pesticides in the concentration range of $10^{-5}$ $\mathrm{M}$ to $10^{-9} \mathrm{M}$ to train a neural network. The biosensor system successfully identified and quantified all samples where organophosphate pesticides were present in water, food and vegetable. The biosensor arrays and automated instrument were evaluated in situ in field experiments where the instrument was successfully applied for analysis of a range of environmental samples [37]. Febbraio et al. [38] demonstrated the possibility to use the esterase 2 from Alicyclobacillus acidocaldarius for the detection of paraoxon a organophosphate pesticide in water as well as in spiked fruit juices. The inhibitory effects of other pesticides on esterase 2 were also investigated, which showed a better selectivity with respect to nonspecific reaction of acethylcholinesterases. The applied methodology allowed one to detect $2.75 \times 10^{-3} \mathrm{ppm}$ of neurotoxic agent, comparable to the efficiency of other acethylcholinesterase-based biosensors. A raw biosensor was devised and tested for paraoxon detection, based on EST2 immobilized on nitrocellulose membrane which showed longtime stability and reproducibility. Using AChE immobilized on gold nanoparticles (AuNPs) and MWNTs composite Xiangyou et al. [39] developed a sensitive, fast and stable amperometric sensor for quantitative determination of OPs insecticide. AuNPs and MWNTs promoted electron transfer reactions at a lower potential and catalyzed the electro-oxidation of thiocholine, thus increasing detection sensitivity. Based on the inhibition principle, under optimal conditions the detection range for trichlorfon was from $10 \mu \mathrm{g} / \mathrm{L}$ to $10 \mathrm{mg} / \mathrm{L}$ with a detection limit of $0.01 \mu \mathrm{g} / \mathrm{L}$. Noguer et al. [40] demonstrated that incorporation of poly (3,4-ethylenedioxythiophene) (PEDOT) a conducting ink in AChE based screen printed biosensors acted not only as a conducting template but also as an electrochemical mediator for thiocholine oxidation. Highly sensitive AChE based screen-printed biosensors were constructed using both classical and enzymatic PEDOT, in combination with genetically modified AChE. These electrodes allowed the measurement of thiocholine oxidation at potentials of $100 \mathrm{mV}$ versus $\mathrm{Ag} / \mathrm{AgCl}$ reference electrode through the mediation of PEDOT. Inhibition of thiocholine production in presence of chlorpyriphos-oxon allowed for detection of this pesticide in concentrations as low as $1 \times 10^{-10} \mathrm{M}$.

In 2012, Mishra et al. [41] described the development of an inexpensive, sensitive, portable, non-invasive sensor which provides real-time results. This automated flow-based biosensor employs genetically modified AChE enzymes B394, B4 and wild type B131. The biosensor was based on a screen printed carbon electrode (SPE) that was integrated into a flow cell. Enzymes were immobilized on cobalt (II) phthalocyanine (CoPC) modified electrodes by entrapment in a photocrosslinkable polymer (PVA-AWP). The automated flow based biosensor was successfully used to quantify three organophosphate pesticides (chlorpyriphos-oxon, ethyl paraoxon and malaoxon) in milk samples. This biosensor was used to produce calibration data in milk with three OPs in the concentration range of $5 \times 10^{-6} \mathrm{M}$ to $5 \times 10^{-12} \mathrm{M}$. It was reported that automated flow-based biosensor successfully quantified the organophosphate pesticides in different fat-containing milk samples. Constructed biosensors showed no false positives or false negatives observation and it could provide rapid detection of highly toxic organophosphate pesticides in food matrices such as milk [41]. Mishra et al. [42] also reported the development of cost-effective column based biosensor for detoxification of organophosphate pesticides in water and milk where phosphotriesterase was immobilized on an activated Sepharose 4B via covalent coupling using an Omnifit glass column. Three different organophosphate pesticides, ethyl paraoxon, malaoxon and chlorpyriphos-oxon were spiked in water and milk to test the detoxification of organophosphate pesticides. Mixtures of these pesticides were also tested to check the cumulative detoxification in the real samples. The efficiency of detoxification was evaluated using previously developed flow based AChEB394 biosensor. Liu et al. [43] reported a highly sensitive organophosphate pesticides amperometric biosensor which was developed by immobilizing AChE through covalent bonding to 1-butyl- 3-methylimidazolium hexafluorophosphate (BMIMPF 6)-graphene- chitosan composite. Graphene 
provided a high specific surface area and the BMIMPF 6 , BMIMPF 6-graphene- chitsoan composite provided a high ionic conductivity. The combination of graphene and BMIMPF 6 catalyzed the electro-oxidation of thiocholine product, thus amplifying the detection sensitivity through a strong synergistic effect. The detection of malathion was proportional to its inhibition concentration ranging from $0.1 \mathrm{nM}$ to $1.0 \mathrm{nM}$ and $1.0 \mathrm{nM}$ to $10 \mathrm{nM}$, with a detection limit of $0.04 \mathrm{nM}$. Ivanov et al. [44] reported a flow-injection system with integrated amperometric biosensor featuring an easily replaceable immobilized AChE membrane. The amperometric biosensor was constructed on the basis of site-specific immobilization of AChE on a hybrid polymer membrane with integrated MWCNTs. It gave a linear response to $\mathrm{ATCl}$ from $2 \mu \mathrm{M}$ to $100 \mu \mathrm{M}$. The sensitivity of the constructed biosensor was $0.093 \mu \mathrm{A} / \mu \mathrm{M} / \mathrm{cm}$. The method had a low detection limit for three OPs in model pesticide solutions ethyl paraoxon $\left(0.9 \times 10^{-12} \mathrm{M}\right)$, monocrotophos $\left(1.8 \times 10^{-12} \mathrm{M}\right)$ and dichlorvos $\left(2.0 \times 10^{-12} \mathrm{M}\right)$.

In 2013, Gong et al., developed a highly sensitive flow injection/amperometric biosensor for the detection of OPs pesticides using layered double hydroxides (LDHs) as the immobilization matrix of AChE. LDHs provided a biocompatible microenvironment due to the intrinsic properties of LDHs. The analytical conditions for the above system were optimized by using methyl parathion. The inhibition of MP was proportional to its concentration ranging from 0.005 to $0.3 \mu \mathrm{g} / \mathrm{mL}$ and 0.3 to $4.0 \mu \mathrm{g} / \mathrm{mL}$ with a detection limit $0.6 \mathrm{ng} / \mathrm{mL}$ [45]. Chen \& Yang [46] reported a biosensor for detecting organophosphate pesticides by using liquid crystal (LC). The principle and advantage of the biosensor is the detection of minute $\mathrm{pH}$ changes during the enzymatic hydrolysis of organophosphate pesticides. The organophosphate pesticides is hydrolyzed by paraoxonase 1 (PON1) immobilized on a copper grid which also hosts $\mathrm{pH}-$ sensitive LC, 4-cyano-4'-pentylbiphenyl (5CB) doped with $0.3 \%$ of 4'-pentyl- biphenyl-4-carboxylic acid (PBA). Proximity of enzyme to $\mathrm{LC}$ is important to ensures that $\mathrm{H}+$ can be detected by the $\mathrm{pH}$-sensitive LC, if not it will be neutralized by buffer. When the organophosphate pesticides is hydrolysed by the enzyme a color change in LC is seen. For paraoxon detection, one can reach a limit of detection (LOD) of $1 \mu \mathrm{M}$ by using the naked eye [46]. Liu et al. [47] in a modification reported a whole-cell biocatalyst/biosensor for the detoxification and detection of organophosphates through display of multiple heterologous proteins on the Escherichia coli cell surface. The co display of $\mathrm{OPH}$ and methyl parathion hydrolase (MPH)-green fluorescent protein (GFP) fusion on the cell surface of Escherichia coli occurred using the truncated ice nucleation protein (INPNC) and Lpp-OmpA as the anchoring motifs. The fluorescence of surfacedisplayed GFP is very sensitive to environmental $\mathrm{pH}$ change. Because hydrolysis of organophosphate pesticides by OPH or MPH generates protons, the recombinant E. coli was used as a whole-cell biosensor for the rapid detection of organophosphate pesticides by evaluating fluorescence changes as a function of organophosphate pesticide concentrations [47].

\section{From 2014 to present}

In 2014, Liang et al. [48] developed a new, highly sensitive and selective electrochemiluminescence (ECL) biosensor for the detection of organophosphate pesticides. A highly sensitive graphene nanosheets-anchored- CdTe quantum dots -based signal-on ECL biosensor was developed combined with the AChE enzymatic reactions for sensing organophosphate pesticides. The conditions for organophosphate pesticides detection were optimized by using methyl parathion. Under the optimized experimental conditions, such a newly designed system showed remarkably improved sensitivity and selectivity and detection limit was found to be as low as about $0.06 \mathrm{ng} / \mathrm{mL}$. In 2015, Wei \& Wang [49] developed a novel AChE biosensor, based on honeycomb-like hierarchically ion liquids ([BSmim] HSO4)-AuNPs-porous carbon composite modified boron-doped diamond (BDD) electrode, for the detection of organophosphate pesticides. The [BSmim]HSO4-AuNPs-porous carbon modified BDD electrode was confirmed by cyclic voltammogram and electrochemical impedance spectroscopy. For the oxidation of thiocholine, hydrolysis product of acetylthiocholine, the peak current at AChE/[BSmim]HSO4-AuNPs-porous carbon/BDD electrode was more than 4.5 times that at AChE/BDD electrode. The inhibition of dichlorvos was linearly proportional to its concentration in the range of $10-10-10^{-6} \mathrm{~g} / \mathrm{L}\left(4.5 \times 10^{-13}-4.5 \times 10^{-}\right.$ $\left.{ }^{9} \mathrm{M}\right)$, with the detection limit of $6.61 \times 10^{-11} \mathrm{~g} / \mathrm{L}\left(2.99 \times 10^{-13} \mathrm{M}\right)$ [49]. Mulyasuryani \& Prasetyawan [50] developed an enzyme biosensor consisting of a pair of SPCEs. The electrodes was optimized with respect to surface area $\left(3,5\right.$, and $\left.7 \mathrm{~mm}^{2}\right)$. OPH enzyme was isolated from Pseudomonas putida, and purified by the ammonium sulfate precipitation method as $6444 \mathrm{ppm}$ (A) and 7865ppm (B). The organophosphate pesticide samples were in the range of $0-100 \mathrm{ppb}$. Results showed that the best performance of the biosensor was achieved by the enzyme A with an electrode area of $5 \mathrm{~mm}^{2}$. The sensitivity of the biosensor was between 3 and $32 \mu \mathrm{S} / \mathrm{ppb}$, and the detection limit for the organophosphate pesticides was $20 \mathrm{ppb}$ (chlorpyrifos), 30ppb (malathion), $40 \mathrm{ppb}$ (diazinon), and 40ppm (profenofos). Based on artificial neural network (ANN) Mishra et al. [51] reported an automatic flow based biosensor to detect binary (chlorpyriphosoxon and malaoxon) organophosphate pesticides mixtures in milk. In order to model the combined response of chlorpyriphosoxon and malaoxon, a total set of 19 mixtures were prepared using ANN. The modeling was validated with an external test of 6 milk samples spiked with chlorpyriphos-oxon and malaoxon. Dominguez et al. [52] developed a novel magnetic particles based electrochemical biosensor for organophosphate insecticide detection in flow injection analysis. This work described a novel configuration strategy to integrate magnetic nanobeads into the flow based system to achieve the reproducible and renewable sensing surface. The designed flow based sensor was demonstrated for the detection of OPs insecticides using AChE enzyme. Kim et al. [53] developed a whole-cell based spectrophotometric biosensor using Escherichia coli expressing $\mathrm{OPH}$ in the periplasmic space attached to single-walled carbon 
nanotube film. Paraoxon was hydrolyzed using this device, and detected by measuring the concentration of the enzymatic reaction product, p-nitropheno. Long et al. [54] reported a novel nanosensor for OPs pesticides based on the fluorescence resonance energy transfer (FRET) between NaYF4: Yb, Er up conversion nanoparticles (UCNPs) and gold nanoparticles (AuNPs). The detection mechanism is based on the facts that AuNPs quench the fluorescence of UCNPs and OPs pesticides inhibit the activity of AChE. Under the optimized conditions, the logarithm of the pesticides concentration was proportional to the inhibition efficiency. The detection limits of parathionmethyl, monocrotophos and dimethoate reached were 0.67 , 23 and 67ng/L respectively. Kaur \& Srivastava [55] developed a polyaniline-zeolite nanocomposite material based AChE biosensor. They reported that the polyanilinenanocrystalline zeolite based AChE biosensor exhibited much higher activity when compared to conventional polyaniline. The performance of the developed biosensor was demonstrated using apple, cabbage, tap water, and river water samples for pesticide determination. Bao et al. [56] reported on a new cost-effective plant esterase-chitosan/gold nanoparticles-graphene nanosheet (PLaE-CS/AuNPs-GNs) biosensor for the sensitive detection of methyl parathion and malathion. The plant esterase shares the same inhibition mechanism as acetylcholinesterase with organophosphate pesticides. The PLaE-CS/AuNPs-GNs composite-based biosensor measured as low as 50ppt $(0.19 \mathrm{nM})$ of methyl parathion and $0.5 \mathrm{ppb}(1.51 \mathrm{nM})$ of malathion with a calibration curve up to $200 \mathrm{ppb}(760 \mathrm{nM})$ and $500 \mathrm{ppb}$ (1513.5nM) for methyl parathion and malathion, respectively [56].

In 2016, Jiang et al. [57] reported an electrochemical biosensor for detection of methyl parathion residue in Fritillaria thunbergii, a medicinal plant cultivated for several thousand years using an electrode modified with acetylcholinesterase immobilized on gold nanoshpere (Au NS). The combination of acetylcholinesterase and Au NS displayed a strong synergetic effect wherein $\mathrm{Au}$ NS could catalyze the oxidation of the enzymatically produced thiocholine resulting in high sensitivity. Li et al. [58] reported on a sensitive amperometric biosensor for organophosphate pesticides by modifying the glassy carbon electrode with AChE immobilized on graphene/polyaniline (G/PANI) composite film. The composite films exhibited large specific area, high conductivity, good biocompatibility and fast redox properties. The as-prepared biosensor showed high affinity to acetylthiocholine (ATCl) with a Michaelis-Menten constant value of $0.20 \mathrm{mmol} / \mathrm{L}$ and a detection limit of 20ng/ $\mathrm{mL}$ for organophosphate pesticides [58]. Lang et al. [59] reported a sensitive amperometric AChE biosensor, based on gold nanorods (AuNRs). Compared with $\mathrm{Au}-\mathrm{Ag}$ heterogeneous NRs, AuNRs exhibited excellent electrocatalytic properties, which can electrocatalytically oxidize thiocholine, at +0.55 $\mathrm{V}$ (vs. SCE). Based on inhibition of AChE the biosensor could detect paraoxon in the linear range from $1 \mathrm{nM}$ to $5 \mu \mathrm{M}$ and dimethoate in the linear range from $5 \mathrm{nM}$ to $1 \mu \mathrm{M}$, respectively. Wang et al. [60] reported a new electrochemical biosensor based on Pd wormlike nanochains/graphitic carbon nitride (Pd WLNCs/g- $\mathrm{C}_{3} \mathrm{~N}_{4}$ ) nanocomposites and AChE. The Pd WLNCs/gC3N4 nanocomposites could effectively immobilize enzyme and promote the signal amplification. Under the optimum condition, the proposed biosensor displayed good performance. The linear response range for the determination of organophosphate pesticides was $1.00 \mathrm{nM}$ to $14.96 \mu \mathrm{M}$ [60]. Luan et al. [61] reported inkjet-assisted layer-by-layer (LbL) microarrays of quantum dots (QDs) and AChE for highly sensitive detection of organophosphate pesticides. In the presence of organophosphate pesticides the AChE activity was inhibited resulting in changes in the fluorescent intensity of QDs/AChE microscopic dot arrays. The QDs/AChE microscopic dot arrays were used for the sensitive visual detection of organophosphate pesticides. Linear calibration for parathion and paraoxon was obtained in the range of $5-100 \mu \mathrm{g} / \mathrm{L}$ under the optimized conditions with the limit of detection (LOD) of $10 \mu \mathrm{g} / \mathrm{L}$. Sundarmurugasan et al. [62] developed the simultaneous detection of monocrotophos and dichlorvos in orange samples using acetylcholinesterasezinc oxide modified platinum electrode with linear regression calibration. In this context, an acetylcholinesterase modified Pt working electrode was fabricated using zinc oxide nanospheres as a nano-interface. An analytical method for the simultaneous detection of monocrotophos and dichlorvos was constructed by establishing 24 linear regression models and error analysis was performed to verify the practicability of these models. The developed biosensor achieved a detection limit of monocrotophos and dichlorvos with detection limits of 0.036 and $0.012 \mathrm{nM}$ respectively. Zheng et al. [63] developed a new type of organophosphate pesticide biosensor wherein AChE was cross-linked on a glassy carbon electrode (GCE) modified with ionic liquid functionalized graphene (IL-GR), Co304 nanoparticles and chitosan (CHI). IL-GR and $\mathrm{Co}_{3} \mathrm{O}_{4}$ nanoparticles not only enhanced the surface area of the modified electrode for enzyme immobilization but also facilitated the electron transfer, resulting in the biosensor displaying a high sensitivity. The fabrication process was characterized by cyclic voltammetry (CV) and electrochemical impedance spectroscopy (EIS) and it was observed that the peak current for oxidation of thiocholine at the AChE/ILGR/ $\mathrm{Co}_{3} \mathrm{O}_{4} / \mathrm{CHI} / \mathrm{GCE}$ electrode is larger than those at AChE/IL-GR/CHI/GCE and AChE/ $/ \mathrm{Co}_{3} \mathrm{O}_{4} / \mathrm{CHI} / \mathrm{GCE}$ electrodes. A linear relationship was found between the inhibition percentage (I\%) and logarithm of the concentration of dimethoate in the range from $5.0 \times 10^{-12}$ to $1.0 \times 10^{-7} \mathrm{M}$, with a detection limit of $1.0 \times 10^{-13} \mathrm{M}$. Kaur et al. [64] developed a conducting polymer and MWCNTs nanocomposite based amperometric biosensor. Nanocomposite consisting of conducting polymer (CP)-Poly(3,4ethylenedioxythiophene) (PEDOT) and MWCNTs was deposited electrochemically onto the surface of fluorine doped tin oxide (FTO) sheets for the analysis of malathion. The detection limit for malathion was $1 \mathrm{fM}$ within the linear range $1 \mathrm{fM}$ to $1 \mu \mathrm{M}$. The storage stability and reusability of the prepared bioelectrode was 
observed to be 30 days and seven times, respectively. Recoveries of malathion from the spiked lettuce sample ranged between 96$98 \%$ using the developed bioelectrode. Bao et al. [65] reported a novel biosensor for rapid, sensitive and selective monitoring of p-nitrophenyl substituted organophosphate pesticides in aqueous system using a functional nanocomposite consisting of elastin-like-polypeptide-organophosphate hydrolase (ELP$\mathrm{OPH}$ ), bovine serum albumin (BSA), titanium dioxide nanofibers $\left(\mathrm{TiO}_{2} \mathrm{NFs}\right)$ and carboxylic acid functionalized multi-walled carbon nanotubes (c-MWCNTs). ELP-OPH served as biocatalyst for organophosphate pesticides, BSA was used to stabilize $\mathrm{OPH}$ activity in the nanocomposite, $\mathrm{TiO}_{2} \mathrm{NFs}$ was employed to enrich organophosphates in the nanocomposite due to its strong affinity with phosphoric group in organophosphate pesticides and c-MWCNTs was used to enhance the electron transfer in the amperometric detection as well as for covalent immobilization of ELP-OPH. Under the optimized operating conditions, the ELP-OPH/BSA/TiO ${ }_{2}$ Fs/c-MWCNTs based biosensor showed a wide linear range, a fast response time (less than $5 \mathrm{~s}$ ) and limits of detection $(\mathrm{S} / \mathrm{N}=3)$ as low as $12 \mathrm{nM}$ and $10 \mathrm{nM}$ for methyl parathion and parathion, respectively.

In 2017, Mishra et al. [66] improved the sensitivity and stability of the previously developed for Sphingomonas $s p$. based optical microplate biosensor for the detection of methyl parathion when silica nanoparticles (Si NP) functionalized with polyethyleneimine (PEI) were integrated with Sphingomonas $s p$. cells. A detection range of 0.1-1ppm MP was achieved after integration with fSi NP which is in the range of MRL value of methyl parathion. Storage stability of biohybrid was also enhanced ten times from 18 to 180 days. This study thus proves that biosensor sensitivity and stability was improved after interaction of cells with fSi NP.

\section{Conclusion}

In conclusion, this review summarizes the previous and current aspects on biosensors for detection of organophosphate pesticides. Recent developments are mostly based on the benefit of nanomaterials to increase the transduction and thus increase the sensitivity of biosensor upto permitted level.

\section{References}

1. Kumar P, Kim KH, Deep A (2015) Recent advancements in sensing techniques based on functional materials for organophosphate pesticides Biosensors and Bioelectronics, 70: 469-481.

2. Liu S, Yuan L, Yue X, Zheng Z, Tang Z, (2008) Recent Advances in Nanosensors for Organophosphate Pesticide Detection. Adv Powder Technol 19: 419-441.

3. http://www.fao.org/3/ea20b790-4a84-57fc-aa98-a367a012ddb8/ i2215e.pdf

4. http://www.fao.org/docrep/018/i3300e/i3300e.pdf

5. Eddleston M, Buckley NA, Eyer P, Dawson AH (2008) Management of acute organophosphorus pesticide poisoning. Lancet 371(9612): 59607.

6. Chowdhary S, Bhattacharyya R, Banerjee D (2014) Acute organophosphorus poisoning. Clinica Chimica Acta 431: 66-76.
7. Van Dyk JS, Pletschke B (2011) Review on the use of enzymes for the detection of organochlorine, organophosphate and carbamate pesticides in the environment. Chemosphere 82(3): 291-307.

8. Fukuto TR (1990) Mechanism of action of organophosphorus and carbamate insecticides. Environ. Health Perspect 87: 245-254.

9. Hayes WJ, Laws ER (1991) In Handbook of Pesticide Toxicology. Academic Press, Inc, San Diego.

10. http://www.epa.gov/opp00001/cumulative/rra-op/pr.htm

11. http://www.epa.gov/opp00001/factsheets/opworkers.htm

12. Turner (1987) APF Turner, I Karube, GS Wilson (Eds.), Biosensors Fundamentals and Applications, Oxford University Press, Oxford, UK.

13. D'Souza SF (2001) Immobilization and stabilization of biomaterials for biosensor applications. Appl Biochem Biotech 96(1-3): 225-238.

14. Skládal P (1996) Biosensors based on cholinesterase for detection of pesticides Food Technology and Biotechnology 34 (1): 43-49.

15. Rekha K, Thakur MS, Karanth NG (2000) Biosensors for the detection of organophosphorous pesticides. Critical Reviews in Biotechnology 20 (3): 213-235.

16. Mulchandani A, Chen W, Mulchandani P, Wang J, Rogers KR (2001) Biosensors for direct determination of organophosphate pesticides. Biosensors and Bioelectronics 16(4-5): 225-230.

17. Suri CR, Raje M, Varshney GC (2002) Immunosensors for pesticide analysis: Antibody production and sensor development. Critical Reviews in Biotechnology 22(1): 15-32.

18. Trojanowicz M (2002) Determination of pesticides using electrochemical enzymatic biosensors. Electroanalysis 14(19-20): 1311-1328.

19. Amine A, Mohammadi H, Bourais I, Palleschi G (2006) Enzyme inhibition-based biosensors for food safety and environmental monitoring. Biosens Bioelectro 21(8): 1405-1423.

20.Zhang YD, Yang BL (2006) Study on characteristic of biosensors associated with cholinesterase for detection of pesticide residues. Journal of hygiene research 35 (2): 250-253.

21. Dzyadevych SV, Soldatkin AP, El'skaya AV, Martelet C, Jaffrezic-Renault $N$, et al. (2006) Enzyme biosensors based on ion-selective field-effect transistors. Anal Chim Acta 568 (1-2): 248-258.

22. Anzai J (2006) Use of biosensors for detecting organ phosphorus agents. Yakugaku Zasshi 126 (12): 1301-1308.

23. Pohanka M, Jun D, Kalasz H, Kuca K (2008) Cholinesterase biosensor construction-A review. Protein and Peptide Letters 15 (8): 795-798.

24. Pohanka M, Musilek, K, Kuca K (2009) Progress of biosensors based on cholinesterase inhibition. Current Medicinal Chemistry 16(14): 17901798.

25. Liang HC, Hay MT (2011) Analytical methods for pesticides and herbicides. Water Environment Research 83(10): 956-982.

26. Rassaei L, Marken F, Sillanpää M, Amiri M, Cirtiu CM, et al. (2011) Nanoparticles in electrochemical sensors for environmental monitoring. TrAC-Trends in Analytical Chemistry 30(11): 1704-1715.

27. Marrazza G (2014) Piezoelectric biosensors for organophosphate and carbamate pesticides: A review. Biosensors 4(3): 301-317.

28. Zhang W, Asiri AM, Liu D, Du D, Lin Y, et al. (2014) Nanomaterialbased biosensors for environmental and biological monitoring of organophosphorus pesticides and nerve agents. TrAC - Trends in Analytical Chemistry 54: 1-10.

29. Kumar J, Melo JS (2015) Microbial biosensors for methyl parathion: From single to multiple samples analysis. Advances in Biosensors Research pp. 89-111. 
30. Kumar J, Jha SK, D’Souza SF (2006) Optical microbial biosensor for detection of methyl parathion pesticide using Flavobacterium sp. whole cells adsorbed on glass fiber filters as disposable bio component Biosens Bioelectron 21 (11): 2100-2105.

31. Kumar J, D’Souza SF (2011) Microbial biosensor for detection of methyl parathion using screen printed carbon electrode and cyclic voltammetry. Biosens Bioelectron 26(11): 4289-4293.

32. Kumar J, D’Souza SF (2010) An optical microbial biosensor for detection of methyl parathion using Sphingomonas sp. immobilized on micro plate as a reusable bio component. Biosens Bioelectron 26(4): 1292-1296.

33. Kumar J, D’Souza SF (2011) Immobilization of microbial cells on inner epidermis of onion bulb scale for biosensor application. Biosens Bioelectron 26(11): 4399-4404.

34. Du D, Wang M, Cai J, Zhang A (2010) Sensitive acetyl cholinesterase biosensor based on assembly of $\beta$-cyclodextrins onto multiwall carbon annotates for detection of organophosphates pesticide Sensors and Actuators. B: Chemical 146 (1): 337-341.

35. Du D, Ye X, Cai J, Liu J, Zhang A, et al. (2010) Acetyl cholinesterase biosensor design based on carbon nanotube-encapsulated polypyrrole and polyaniline copolymer for amperometric detection of organophosphates. Biosens Bioelectron 25(11): 2503-2508.

36. Ion AC, Ion I, Culetu A, Gherase D, Moldovan CA, et al. (2010) Acetyl cholinesterase voltammetry biosensors based on carbon nanostructure-chitosan composite material for organophosphate pesticides. Materials Science and Engineering C 30(6): 817-821.

37. Crew A, Lonsdale D, Byrd N, Pittson R, Hart JP, et al. (2011) A screen-printed, amperometric biosensor array incorporated into a novel automated system for the simultaneous determination of organophosphate pesticides. Biosens Bioelectron 26(6): 2847-2851.

38. Febbraio F, Merone L, Cetrangolo GP, Rossi M, Nucci R, et al. (2011) Thermos table esterase 2 from Alicyclobacillus acidocaldarius as biosensor for the detection of organophosphate pesticides. Analytical Chemistry 83(5): 1530-1536.

39. Xiangyou W, Chen Z, Xia S (2011) Acetyl cholinesterase biosensor design based on the gold nanoparticles and multi-wall carbon annotates modified electrode for amperometric detection of organophosphate pesticides. International Agricultural Engineering Journal 20(1): 47-51.

40. Noguer T, Sikora T, Istamboulie G, Jubete E, Ochoteco E, et al. (2011) Highly sensitive detection of organophosphate insecticides using biosensors based on genetically engineered acetylcholinesterase and poly(3,4- ethylenedioxythiophene). Journal of Sensors 2011: 7.

41. Mishra RK, Dominguez RB, Bhand S, Muñoz R, Marty JL (2012) A novel automated flow-based biosensor for the determination of organophosphate pesticides in milk. Biosensors and Bioelectronics 32(1): 56-61.

42. Mishra RK, Istamboulie G, Bhand S, Marty JL (2012) Detoxification of organophosphate residues using phosphotriesterase and their evaluation using flow based biosensor. Analytica Chimica Acta 745: 64-69.

43. Liu ZM, Wang ZL, Cao YY, Jing YF, Liu YL (2012) Amperometric acetylcholinesterase biosensor based on BMIMPF 6-Graphenechitosan composite for the sensitive detection of organophosphates. Sensor Letters 10(3-4): 941-947.

44. Ivanov Y, Marinov I, Portaccio M, Lepore M, Mita DG, et al. (2012) Flow-injection system with site-specific immobilization of acetylcholinesterase biosensor for amperometric detection of organophosphate pesticides. Biotechnology and Biotechnological Equipment 26 (3): 3044-3053.
45. Gong J, Guan Z, Song D (2013) Biosensor based on acetylcholinesterase immobilized onto layered double hydroxides for flow injection/ amperometric detection of organophosphate pesticides. Biosensors and Bioelectronics 39(1): 320-323.

46. Chen CH, Yang KL (2013) A liquid crystal biosensor for detecting organophosphates through the localized $\mathrm{pH}$ changes induced by their hydrolytic products. Sensors and Actuators B: Chemical 181: 368-374.

47. Liu R, Yang C, Xu Y, Xu P, Jiang H, et al. (2013) Development of a wholecell biocatalyst/biosensor by display of multiple heterologous proteins on the escherichia coli cell surface for the detoxification and detection of organophosphates. J Agric Food Chem 61(32): 7810-7816.

48. Liang H, Song D, Gong J (2014) Signal-on electrochemiluminescence of biofunctional CdTe quantum dots for biosensing of organophosphate pesticides. Biosens Bioelectron 53: 363-369.

49. Wei M, Wang J (2015) A novel acetylcholinesterase biosensor based on ionic liquids-AuNPs-porous carbon composite matrix for detection of organophosphate pesticides. Sensors and Actuators B: Chemical 211: 290-296.

50. Mulyasuryani A, Prasetyawan S (2015) Organophosphate hydrolase in conductometric biosensor for the detection of organophosphate pesticides. Anal Chem Insights 10(1): 23-27.

51. Mishra RK, Alonso GA, Istamboulie G, Bhand S, Marty JL (2015) Automated flow based biosensor for quantification of binary organophosphates mixture in milk using artificial neural network. Sensors and Actuators B: Chemical 208: 228-237.

52. Dominguez RB, Alonso GA, Muñoz R, Hayat A, Marty JL (2015) Design of a novel magnetic particles based electrochemical biosensor for organophosphate insecticide detection in flow injection analysis. Sensors and Actuators B: Chemical 208: 491-496.

53. Kim I, Kim GH, Kim CS, Cha HJ, Lim G (2015) Optical detection of Paraoxon using single-walled carbon nanotube films with attached organophosphorus hydrolase-expressed Escherichia coli. Sensors 15(6): 12513-12525.

54. Long Q Li H, Zhang Y, Yao S (2015) Upconversion nanoparticle-based fluorescence resonance energy transfer assay for organophosphorus pesticides. Biosens Bioelectron 68: 168-174.

55. Kaur B, Srivastava R (2015) A polyaniline-zeolite nanocomposite material based acetylcholinesterase biosensor for the sensitive detection of acetylcholine and organophosphates. New Journal of Chemistry 39(9): 6899-6906.

56. Bao J, Hou C, Chen M, Li J, Huo D, et al. (2015) Plant Esterase-Chitosan/ Gold Nanoparticles-Graphene Nanosheet Composite-Based Biosensor for the Ultrasensitive Detection of Organophosphate Pesticides. J Agric Food Chem 63(47): 10319-10326.

57. Jiang J, Zhang H, Wang C, Xu Y (2016) Eelectrochemical detection of methyl parathion in Fritillaria thunbergii based on acetylcholinesterase immobilized gold nanoshpere. International Journal of Electrochemical Science 11(7): 5481-5489.

58. Li Y, Zhang Y, Han G, Xiao Y, Li M, et al. (2016) An Acetylcholinesterase Biosensor Based on Graphene/Polyaniline Composite Film for Detection of Pesticides. Chinese Journal of Chemistry 34(1): 82-88.

59. Lang Q Han L, Hou C, Wang F, Liu A (2016) A sensitive acetylcholinesterase biosensor based on gold nanorods modified electrode for detection of organophosphate pesticide. Talanta 156157: 34-41.

60. Wang B, Ye C, Zhong X, Chai Y, Chen S, et al. (2016) Electrochemical Biosensor for Organophosphate Pesticides and Huperzine-A Detection Based on Pd Wormlike Nanochains/Graphitic Carbon Nitride Nanocomposites and Acetylcholinesterase. Electroanalysis 28(2): 304311. 
61. Luan E, Zheng Z, Li X, Gu H, Liu S (2016) Inkjet-assisted layer-by-layer printing of quantum dot/enzyme microarrays for highly sensitive detection of organophosphorous pesticides. Anal Chim Acta 916: 77 83.

62. Sundarmurugasan R, Gumpu MB, Ramachandra BL, Nesakumar N, Sethuraman S, et al. (2016) Simultaneous detection of monocrotophos and dichlorvos in orange samples using acetylcholinesterase-zinc oxide modified platinum electrode with linear regression Calibration. Sensors and Actuators B: Chemical 230: 306-313.

63. Zheng Y, Liu Z, Zhan H, Li J, Zhang C (2016) Studies on electrochemical organophosphate pesticide (OP) biosensor design based on ionic

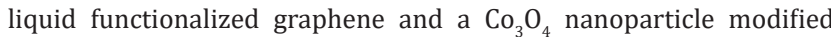
electrode. Analytical Methods 8(26): 5288-5295.
64. Kaur N, Thakur H, Prabhakar N (2016) Conducting polymer and multi-walled carbon nanotubes nanocomposites based amperometric biosensor for detection of organophosphate. Journal of Electroanalytical Chemistry 775: 121-128.

65. Bao J, Hou C, Dong Q, Ma X, Chen J, et al. (2016) ELP-OPH/BSA/TiO nanofibers/c-MWCNTs based biosensor for sensitive and selective determination of p-nitrophenyl substituted organophosphate pesticides in aqueous system. Biosens Bioelectron 85: 935-942.

66. Mishra A, Kumar J, Melo JS (2017) An optical microplate biosensor for the detection of methyl parathion pesticide using a biohybrid of Sphingomonas sp. cells-silica nanoparticles. Biosens Bioelectron 87: 332-338.

\section{Your next submission with Juniper Publishers will reach you the below assets}

- Quality Editorial service

- Swift Peer Review

- Reprints availability

- E-prints Service

- Manuscript Podcast for convenient understanding

- Global attainment for your research

- Manuscript accessibility in different formats

(Pdf, E-pub, Full Text, Audio)

- Unceasing customer service

Track the below URL for one-step submission https://juniperpublishers.com/online-submission.php 